\title{
Sociotechnological Perspective on the Development of Lunar and Martian Infrastructures Made of Concrete Materials
}

\author{
Dicky Rezady Munaf ${ }^{1^{*}}$, Yasraf Amir Piliang ${ }^{1^{* *}}$ \\ ${ }^{1}$ Research Group of Humanities, Sociotechnology, Faculty of Arts and Design, Institut Teknologi Bandung, Jl. \\ Ganesa 10, Bandung, 40132, Indonesia
}

\begin{abstract}
Space exploration activities have long taken place to discover the shape of our solar system and the way all of its components work together. The closest celestial bodies to the Earth that are regarded by researchers as capable of becoming colonies are Moon and Mars. One challenge for researchers is the mission of developing permanent infrastructures on both Moon and Mars. The testing of casting technology on both Moon and Mars has been done in relation with the mission. The material resources on both Moon and Mars have been developed for cement and casting materials. Since the space mission for human colony development on both Moon and Mars is considered extraordinary, a sociotechnological approach would be necessary in order to realize the development. This approach will play its role in making people ready to accept the advancement of sciences and technologies.
\end{abstract}

Keywords: Concrete; Infrastructure; Sociotechnology; Mars; Moon

\section{Introduction}

The closest celestial body in our solar system that resembles the Earth is Moon. Studies of Moon were done using a telescope by Galileo in 1609 (Galileo, 1610), long before humans and their technologies were able to directly touch the surface of Moon. Further observation of Moon's rocky surface has indicated that it shares similar geological processes, such as geochemistry and geophysics, with the Earth's surface (Hiesinger and Head, 2006). In addition, a lot of modern exploration has expanded to Mars, such as Mariner 4 in the early 1960s and its return in 1965 to capture the first close-up images, and Mariner 9 in 1971 (Martinez et al., 2017).

From the late 1950s through the 1960s, an agreement was made between countries on the development of outer space-then between the US and the Soviet Union (U.S.-Soviet Cooperation in Space, 1985). In that era, another country that conducted research in space was Japan. Japan's space research activities began in 1969. From 1998 to 2007, Japan developed a security sector policy in space (Kallender, 2016). The successful launch of Sputnik in 1957 marked the beginning of the era of space exploration. The next stage of space exploration, to send humans into outer space, as initiated through the Apollo project, with its goal of landing human beings on Moon (Mendall, 1998; Launius, 2006). This goal was also aimed to respond to Urey's claim that Moon was an unidentified primitive object in space (Urey, 1966). The claim was made before Apollo 11 managed to bring back the sam samples resulting from the exploration on Moon. 
The space utilization program (mainly lunar program), as a resource, was also spurred in Europe through the organization of the European Space Agency (ESA). The SMART-1 mission, launched in the early 2000s to examine lunar origins and evolution, indicated that ESA was serious about space project activities (Foing et al., 2016). The next ESA exploration concept, Moon Village project, was proposed with the aim of enabling both humans and robots to perform activities on Moon on a sustainable basis. In order to realize the major space project on Moon, the International Lunar Exploration Working Group (ILEWG), founded in 1994, collaborated with the ESA project (Foing, 2017). With cooperation among several countries, the basic ambition of the development of Moon Village project was to establish a permanent Moon-based station. The science and technology playing a role in Moon Village project was considered a means of education for the younger generation. The structure, which combined automation, robotics, and humanity, was put forward in designing the facility's architecture for a civilization on Moon (Messina, 2016).

In 2003, India participated in designing a mission to Moon, whose implementation was scheduled for 2008. The mission was equipped with X-ray spectrophotometer and stereographic equipment to research Moon's North and South Poles. The mission is part of India's 2020 vision; it is a vision for its Millennium era, where both the sectors of the software industry and the space industry are expected to promote the growth of the agriculture and manufacturing sectors (Dholakia, 2001). In the current century, suitable supply chain management encourages the space logistics infrastructure for sustainable exploration and to serve terrestrial life (Ishimatsu et al., 2016).

The construction of space resources on a large scale has been taking place not just on Moon but also on Mars. At first, the establishments in space received imported material hardware from Earth and then, little by little, the space industry began an expansion to produce the infrastructure for their requirements (Metzger, 2016).The goal of exploration on Mars is not much different from Moon exploration, that is, to create a permanent colony by 2024 (Bizzari et al., 2017). To the present, research on risks for humans to travel in space has been taking place, particularly with the purpose of expansion in the solar system (van Allen, 2004; Mindell et al., 2008; Putman, 2015).

The space era has long since begun. Exploration of the farther reaches of the solar system will continue to be pursued by humans. Geologically related investigations on the surface of Moon and the environment of Mars are being conducted to identify the evolution of Moon and Mars. Most of the minerals found in lunar and Martian soil and rocks (with a few exceptions) are also available on Earth, such as silicon dioxide $\left(\mathrm{SiO}_{2}\right)$, alumina $\left(\mathrm{Al}_{2} \mathrm{O}_{3}\right)$, sulfur ( $\mathrm{S}$ ), and iron (FeO). Another form of extrusive material from volcanic activity that is common and widely found on Moon and Mars is basalt (Nazer, 2019). The field observation about rocks on the surface of Moon and Mars was done for the infrastructure development on both. One of the technologies that is being developed is concretion. A later idea was whether both Moon and Mars are feasible for civilization. Durst et al. (2016) revealed that to conduct space exploration, both high levels of science and technology and an understanding of the culture and traditions of humanity are required.

To succeed with the development of concrete or casting material that can be applied to make infrastructure on both Moon and Mars, sociotechnology is needed. New technological designs cannot achieve maximum results on their own, even though they are separate from the human component that has to understand them. It is important to view the technology and the people who work with it as combined within a system; they cannot be maximized as separate entities. Through this rationale, the essential principle of a joint operation emerges, in which it is the role of engineers to act as technological, natural, societal and cultural mediators, otherwise known as a sociotechnological approach (Trist and Bamforth, 1951; Trist et al., 1963; Bell et al., 2012). In a sociotechnological perspective, engineering is presumed to be a sociotechnical activity that leads to development more successfully than 
modern engineering, which speaks in terms of a strictly technological undertaking (Bell et al., 2012).

The sociotechnological approach is important to be used as a parameter in infrastructure development on Moon or Mars. It is important to consider that infrastructure development will not only be conducted on Earth; but if it is to be carried out in space, it is necessary to review the social relations between humans and technology in the future. The use of sociotechnology in general can be done by first testing for similarities of soil on Moon and Mars and then comparing them with the materials found on Earth as raw materials for building infrastructure. This will be important in order to minimize failures when this project is carried out in outer space. This paper will now move to a discussion of the role of sociotechnological approaches in relation to concrete casting materials taken from Moon and Mars.

\section{Analysis of Concrete Material Resources}

The technology of concrete casting has evolved since 1824, and it has become even more sophisticated today. According to the social paradigm, the quality of concrete material lies not only in its strength but also in the mechanical force it generates. The evolution of concrete casting technology cannot be separated from the claim that the weak point of the technology comes from the results of the concrete casting technology itself, called the interfacial zone. This weakness can be well controlled through the "transport mechanism" assessment on the pores of concrete casting media.

The presence of indications that have arisen during the ongoing process of the evolution of concrete casting technology, leading to a thorough knowledge of the possibility of the materials of either Moon or the Mars being impacted by infrastructure loads is required (Lin et al., 1998). Loads may possibly be borne by either Moon's or Mars's surface, such as solar winds, small meteors, and extreme weather. The solidification of the geological structure of the surfaces of both Moon and Mars has resulted from their adaptation to their extreme environmental aspects. The availability of materials from Moon and Mars is a resource that can be utilized for the development of space exploration missions.

In solving the energy problems on both Moon and Mars, NASA has conceived an idea to produce energy. The focus of the conception is to engineer oxygen from carbon dioxide by using zirconia electrolysis cells and solid oxide electrolysis, which is part of the In Situ Propellant Production (ISPP) program. In space, mass is an important component of spaceflight and spacecraft. According to Sanders and Larson (2011), In-Situ Resource Utilization (ISRU) has the capability to extract and process resources at the site of exploration into useful products and infrastructure.

Although such conceptions, including various loads and the microgravity of the environment conditions has been available, the knowledge of the geological structure of Moon and Mars along with detailed characteristics of their materials must also be known for the purpose of making cast concrete. In principle, the materials of both Moon and Mars can be classified into rock, regolith, and breccia when observed from their formations and sizes resulting from either evolution or the impact of meteors (Hartmann, 2019). In general, on Moon, the amount of $\mathrm{CaO}$ is low and less suitable for producing Portland cement. However, research shows that the CaO levels in anorthosite rocks is around $17 \%$ and in basalts, is around $12 \%$, which means that the materials can still be utilized as raw materials for cement production in steamy conditions. Furthermore, in the process where a high evaporation temperature is applied, $\mathrm{CaO}$ levels can also be produced from the rock's materials through the unneeded oxide outages until they reach their melting point. An 
illustration of the lunar surface can be seen in Figure 1. The composition of the surface materials of both Moon and Mars based on observations from various missions and times are shown in Tables 1, 2, and 3.

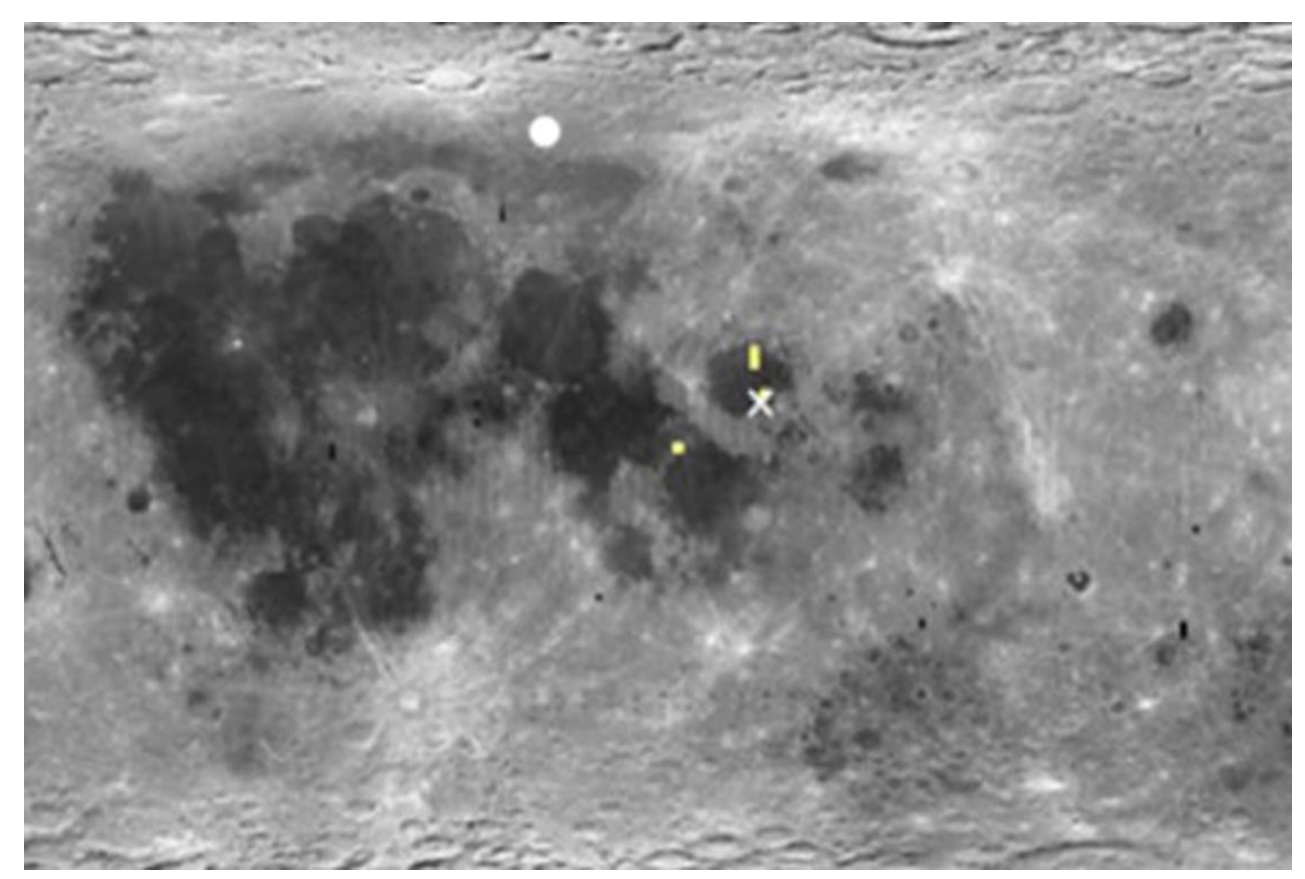

Figure 1 The appearance of regolith and breccia from Luna 24 mission (Diaz et al., 2015)

Table 1 Chemical content of Martian Soil (Lin et al., 1998)

\begin{tabular}{lccc}
\hline \multicolumn{1}{c}{ Oxide } & A-2, Soil \% Weight & A-4, Soil \% Weight & A-5, Soil \% Weight \\
\hline $\mathrm{SiO}_{2}$ & & 43.3 & 43.8 \\
$\mathrm{Al}_{2} \mathrm{O}_{3}$ & & 10.4 & 10.1 \\
$\mathrm{FeO}$ & & 14.5 & 17.5 \\
$\mathrm{CaO}$ & & 4.8 & 5.3 \\
$\mathrm{MgO}$ & 8.7 & 9.0 & 8.6 \\
$\mathrm{SO}_{3}$ & 4.3 & 6.2 & 5.4 \\
$\mathrm{Na}_{2} \mathrm{O}$ & 4.3 & 5.1 & 3.6 \\
$\mathrm{~K}_{2} \mathrm{O}$ & 0.6 & 0.7 & 0.7 \\
$\mathrm{TiO}_{2}$ & 6.3 & 1.1 & 0.7 \\
$\mathrm{MnO}$ & 0.5 & 0.5 & 0.6 \\
\hline
\end{tabular}

Table 2 Chemical content of Martian Rock (location from Viking-Chryse \& Utopia 1976; Pathfinder 1997) (Lin et al., 1998)

\begin{tabular}{lcc}
\hline \multicolumn{1}{c}{ Oxide } & A-3, “Barnacle Bill” \% Weight & A-7, Rock “Yogi” \% Weight \\
\hline $\mathrm{SiO}_{2}$ & 55.0 & 50.3 \\
$\mathrm{Al}_{2} \mathrm{O}_{3}$ & 12.4 & 11.4 \\
$\mathrm{FeO}$ & 12.7 & 13.3 \\
$\mathrm{CaO}$ & 4.6 & 5.8 \\
$\mathrm{MgO}$ & 3.1 & 6.3 \\
$\mathrm{SO}_{3}$ & 2.2 & 4.2 \\
$\mathrm{Na}_{2} \mathrm{O}$ & 4.2 & 2.5 \\
$\mathrm{~K}_{2} \mathrm{O}$ & 1.4 & 1.1 \\
$\mathrm{TiO}_{2}$ & 0.7 & 0.8 \\
$\mathrm{MnO}$ & 0.9 & 0.5 \\
\hline
\end{tabular}


Table 3 Chemical compositions (wt.\%) of Lunar and Martian Soil samples (Toulmin et al., 1977; Greeley et al., 1981; Khitab et al., 2015)

\begin{tabular}{lccc}
\hline Constituent & Lunar Sample & Martian Sample & Cement \\
\hline $\mathrm{SiO}_{2}$ & 37.79 & 44.7 & 20.13 \\
$\mathrm{Al}_{2} \mathrm{O}_{3}$ & 19.66 & - & - \\
$\mathrm{FeO}$ & 6.44 & 8.3 & 1.19 \\
$\mathrm{Fe}_{2} \mathrm{O}_{3}$ & 10.74 & 5.6 & 64.01 \\
$\mathrm{MgO}$ & 8.85 & 5.7 & 5.98 \\
$\mathrm{CaO}$ & 12.97 & 0.9 & 0.37 \\
$\mathrm{~K}_{2} \mathrm{O}$ & 0.05 & $<0.3$ & 0.77 \\
$\mathrm{TiO}_{2}$ & - & 18.2 & 2.35 \\
$\mathrm{SO}_{3}$ & - & 7.7 & - \\
\hline
\end{tabular}

In addition, an important thing that needs to be learned in cast concrete production is the distribution of the size of the existing particles. Another possibility is to mix and place the materials for the concrete production (Chandwani et al., 2015, Yadav et al., 2018). Although the samples from both Moon and Mars consist of some dust and a few rocks, their usage is comparable with the materials of Earth's rock. Another important thing to know in the field of concrete production is the distribution of the sizes of the existing particles because it is necessary for the purpose of surface-dry material mixing (Niken et al., 2017). Even though there are very few samples of sand and rocks from both Moon and Mars, analogous comparisons with Earth's rocks have been made since 1999. Below are examples of these analogies.

- The sand and rocks from the surface of Mars are analogous to the sand and rocks from Hawaii (Phillips, 2012).

- The sand and rocks from Moon's surface are analogous to the sand and rocks from San Francisco (T.D. Lin, personal communication, October 14,1995)—volcanic sand, shiny dark basalt.

Table 4 shows the compositional particle trends of the distributions of sizes in lunar and Martian soil samples. Lunar soil sample trends in the composition were identified with maturity, which means that a large number of meteoroids crashed into the lunar surface and is related to grain size (McKay et al., 1991). Compositional patterns of particle size in lunar soil, according to Colwell et al. (2007), are summarized in Table 7.

Table 4 Distribution of Lunar and Martian Particle sizes (T.D. Lin, personal communication, February 1995; Lin et al., 1998)

\begin{tabular}{ccc}
\hline Size (mm) & Lunar Weight (\%) & $\begin{array}{c}\text { Martian Weight } \\
(\%)\end{array}$ \\
\hline $0.5-1.0$ & 22.0 & 21.1 \\
$0.25-0.5$ & & 29.5 \\
$0.15-0.25$ & & 20.8 \\
$0.09-0.15$ & & 12.9 \\
$0.05-0.09$ & & 9.2 \\
$0.02-0.05$ & 30.5 & 5.4 \\
$0.1-0.5$ & 25.8 & \\
$0.05-0.1$ & 21.7 & \\
$<0.02$ & & 1.3 \\
\hline
\end{tabular}


Table 5 Volume abundances of particles by particle size in Lunar Soil (McKay, cited in Colwell et al., 2007)

\begin{tabular}{cc}
\hline Size $(\mu \mathrm{m})$ & Weight $(\%)$ \\
\hline $250-500$ & 11.91 \\
$150-250$ & 13.13 \\
$90-150$ & 15.99 \\
$75-90$ & 5.48 \\
$45-75$ & 14.45 \\
$20-45$ & 17.37 \\
\hline
\end{tabular}

\section{Experimentation with Fabricating the Concrete}

The production process for cast concrete samples for both Moon and Mars was based on the known chemical composition and particle size distributions. The testing for the limited materials of the cast concrete sample was performed with cubic specimens $5 \times 5 \times 5$ $\mathrm{cm}$ in size for dimensional analysis by applying two combined methods to ensure the coherence of the experiments. At present, there are only two methods:

- Method 1: DMSI (Dry Mix Steam Injection), which was created by T.D. Lin

- Method 2: PAC (Prepacked Aggregate), which was created by Mohammad Sahari Besari

The diagram containing the comparison of the two methods can be seen in Figure 2, which shows the most suitable methods for the development of lunar concrete production (Kanamori et al. cited in Matsumoto et al., 1998). This comparison could happen because most of the materials were processed in pressurized air so that the quality of concrete was easily produced as if it had been manufactured on Earth. The amounts of hydrogen and preprocessing ilmenite required to produce one ton of prepacked aggregate concrete are estimated to be $8 \mathrm{~kg}$ and $598 \mathrm{~kg}$, respectively. To ensure good concrete, other materials should be added, such as water, in order to produce grout cement to make a prepacked aggregate concrete.

The production process of material formation was performed on a trial scale at National Chiao-Tung University, Taiwan. The test results on the materials' attractive force are shown in Table 6. Wan (2015) reported the results of some physical properties of lunar and Martian concrete measurements, which are found in Table 7.

Table 6 Results of simulated compression strength of Lunar Concrete (Lin et al., 1998)

\begin{tabular}{ccc}
\hline $\begin{array}{c}\text { Specimen } \\
\text { (35 days) }\end{array}$ & $\begin{array}{c}\text { Tensile } \\
\text { Strength (psi) }\end{array}$ & W/C \\
\hline LF & 5.300 & 0.81 \\
LA & 5.833 & 0.81 \\
LC & 5.775 & 0.81 \\
\hline
\end{tabular}

Notes:

1) LF $=$ Lunar soil stimulant $<0.8 \mathrm{~mm}$

LA $=$ Lunar soil as received

$\mathrm{LC}=$ Lunar soil stimulant $>0.8 \mathrm{~mm}$

2) Cement $/$ Sand Ratio $=i 2^{-5}$ 

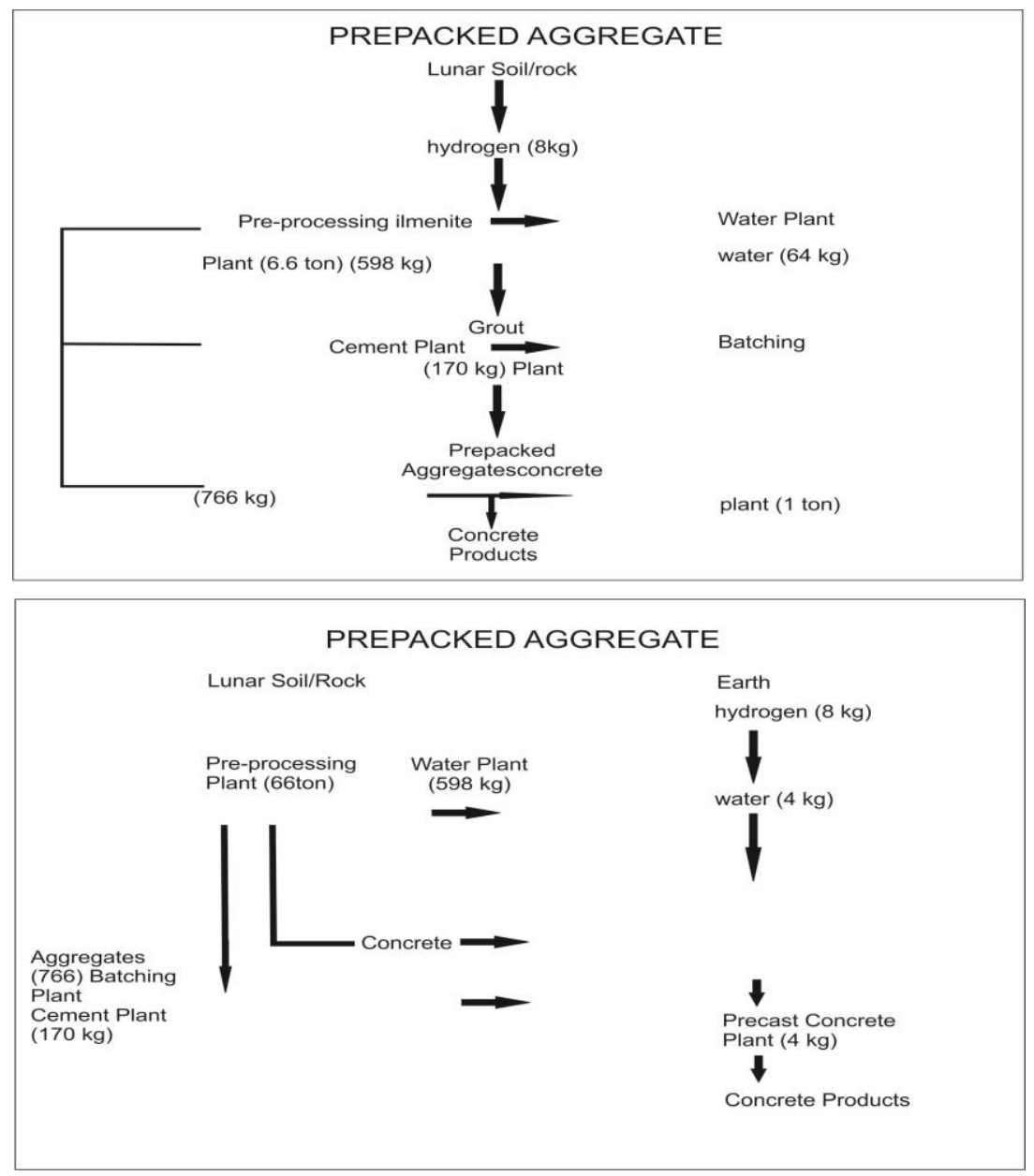

Figure 2 Comparison of DMSI and PAC Methods (Matsumoto et al., 1998)

Table 7 Properties of Lunar and Martian Concrete (Wan, 2015)

\begin{tabular}{lcc}
\hline \multicolumn{1}{c}{ Property } & Lunar Concrete & Martian Concrete \\
\hline Compressive Strength (MPa) & $39-75.7$ & $20-63$ \\
Tensile Strength $(\mathrm{MPa})$ & 8.3 & $2.7-3.6$ \\
Density $\left(\mathrm{kg} / \mathrm{m}^{3}\right)$ & 2600 & - \\
Young's modulus $(\mathrm{GPa})$ & 21.4 & $6.5-10$ \\
Coefficient of thermal & $5.4 \times 10^{-6}$ & - \\
expansion $\left(1 /{ }^{\circ} \mathrm{C}\right)$ & - & 1.65 \\
Bending strength $(\mathrm{MPa})$ & - & \\
\hline
\end{tabular}

Although the two methods have shown that the test results of compression strength are close to equivalent, an assessment of energy production remains to be done. The intensive work on the PAC method was performed by using the calculations from the gravity analysis of the mixed materials of Coutte flow and from the analysis of ground excavation by Poisseule. As a result, the analysis shows that the PAC method uses 33\% less energy than the DMSI method does to produce $1 \mathrm{~m} 3$ of both the lunar and the Martian cast concrete. The scale of value for the PAC method is $3.4 \mathrm{GJ}$, whereas it is $5 \mathrm{GJ}$ for DMSI. This is important to consider when starting the production of cast concrete on both Moon and Mars because energy is required to meet the needs of fuel for the development activities. 
Due to the limited energy availability on both Moon and Mars, efficient utilization of energy is required.

Reis and Ferreira (2004) researched another kind of polymer concrete, epoxy concrete, which is reinforced with synthetic fibers. The composition of this concrete is $80 \%$ sand and $20 \%$ epoxy resin. Another study of polymer-based concrete was conducted by Lee et al. (2014), who used 90\% lunar artificial soil and 10\% polymer in their concrete mixture.

\section{Living on Moon and Mars with the Sociotechnological Approach}

The sociotechnological model has become one of the most widely accepted approaches to research and has been extensively used in the social sciences. The sociotechnological system is explained as an open system with strict roles that must be interrelated and benefit the external world. However, the environment is always dynamic (Emery and Trist, 1973). Sociotechnology has a dual responsibility for managing intra-organizational priorities related to an external product and for adjusting, controlling, and monitoring the research impact on the environment. However, it should also be viewed as a single concept (sociotechnological concepts and environmental factors) to be a good model.

Related to space exploration, it is true enough that the technological instruments to support human life on Moon have been developed in such a way. The decades of exploration have made people increasingly aware of the opportunity to build civilizations beyond the Earth. Within NASA, the ISRU Technology Development Project is currently aimed to increase the human scale for lunar and Martian application. ISRU expansion efforts refer to developing the scale for meeting human mission needs and life support applications (Sanders, 2018). Moreover, ISRU encourages obtaining and using local materials in space when exploring or living on Moon and Mars (or other bodies in the solar system) (Lai and Gertsch, 2013). A survey related to human and robot exploration on Mars was conducted by Holler (2013) through a random sample of 1.101 Americans 18 years and over. The results of the survey showed that as many as $72 \%$ of the respondents agreed that the US government should fund NASA's technological research to send humans to Mars; $84 \%$ of the respondents suggested that NASA establish stronger cooperation with private parties; and $71 \%$ of them were confident that humans could land on Mars by 2033.

Guarino (2017) even wrote to Stephen Hawking, saying that human beings should leave the Earth one day and initiate a space exodus. Stephen Hawking suggested that the world's nations should collaborate and unite in a colony-building project on Moon within 30 years, and he predicted that humans could reach Mars in the next 15 years. That humans basically understand how to survive on Moon is demonstrated by the fact that astronauts can live for many years at the international space station, and future projects for building colonies on both Moon and Mars have long been established. Juarez (2013) mentioned as many as 100,000 people who are eager to live on another planet. Moreover, 30,000 people did not question the cost or survival abilities of living on other planets, especially Mars, as a colony project. The latest news explains why NASA is focusing more on Mars projects than on Moon projects for the 2030s. However, McKay, a NASA astrobiologist, confirms that humans cannot survive on Mars if they are incapable of learning how to live on Moon. This can be interpreted as indicating that Moon is the blueprint for the initiative-driven, habitat, communication, and life support systems for Mars (Fecht, 2016). Apart from that, as stated by Williams (2009), research on human life in outer space, based on psychological and medical approaches, is required since astronauts are humans with a normal psychology who live in an abnormal environment. Bizzari et al. (2017) explained that astronauts could lose $25 \%$ of their muscle mass during the long-term flights. Besides, their disorientation in microgravity would have an effect on the sensors that exist in their body. Therefore, it is 
necessary to conduct research on minimizing the risks to both the human body and human psychology. It can be concluded that even though there are several studies that say it is possible for humans to live on Mars or Moon, a better model is still needed to plan for and reduce failure, and the best model to be used is the sociotechnological approach.

This is so because the sociotechnological model can operate at the meso level of organizations, and it also works at the macro level of community. At the organizational level, the sociotechnological model can be used to optimize the social and technical needs. For instance, if the idea to live on Moon and Mars were to be realized, then the technology would be designed to encourage employees to achieve a balance in the optimum level of quality assurance between intra-organizational considerations and the needs of the external community for safety. In other words, the sociotechnological approach can become a safety standard. This can be done through competence training and by creating an appropriate decentralization of decision-making, combined with "failsafe" technical devices. The sociotechnological approach can become a bridge between technology and human beings since sociotechnology can be used to describe how one factor or variable is related to another factor or variable. This sociotechnical approach can also be used for research as a model or standard operational procedure for safety precautions when relating technology and human beings, and, therefore, we assume that the idea of building infrastructure on Moon and the planet Mars can no doubt be realized in the future.

\section{Conclusions}

The program of space utilization was initiated by NASA in 1994, and some nations have participated in its international collaboration projects since then. The program has challenged civil engineering. The challenge not only relates to the establishment of settlements on both Moon and Mars but also relates to the sociotechnological aspects, mainly their technological spin-offs and methods for infrastructure development.

For the first time ever, the production of concrete on Moon and Mars will be realized soon. This can happen since a sample of Martian rocks arrived on the Earth in 2005. In addition, NASA's upcoming Mars 2020 Perseverance rover mission will collect the first samples from Mars by subsequent missions. Therefore, it can be said that the infrastructure engineering on Moon and Mars is very promising to be done in the future.

However, there are still a lot of problems that have to be solved. Not only does the concrete casting technology need special attention but previous studies related to civil engineering. It also requires further research either in the lunar or Martian environments. The sociotechnological aspects are expected to be able to resolve these problems. In relation to the material casting system on both Moon and Mars sociotechnological aspects can particularly help in the following areas:

- the utilization of the resources of both Moon and Mars in producing cement;

- the application of solar energy for the oxide evaporation process, which is not required in casting;

- the development of production procedures and casting systems in microgravity environments;

- the analysis of required energy and casting technologies for the casting of building structures by applying either the DMSI or the PAC method;

- the performance of microscopic tests of casting results by using either the DMSI or the PAC method to determine the integration of forces in the cast structure;

- the designing of automatic robot control systems for the infrastructure development process on Moon and the Mars; 
- the designing of a concept for Moon's colony stations, whether an inflatable structure or box structure, which includes its ergonomic aspects.

\section{Acknowledgements}

The author expresses his gratitude to Professor Mohammad Sahari Besari and Dr. T.D. Lin for their support on the technical information and for the in-depth discussions on micro-meso-macro technology in concrete manufacturing on both Moon and Mars, including its relation to the sociotechnological perspective.

\section{References}

Bell, S., Chilvers, A., Hillier, J., 2012. The Sociotechnology of Engineering Sustainability. Proceedings of the Institution of Civil Engineers. Engineering Sustainability, Volume 164(3), pp. 177-184

Bizzari, M., Masiello, M.G., Guzzi, R., Cucina, A., 2017. Journey to Mars: A Biomedical Challenge Perspective on Future Human Space Flight. Journal of Biological Sciences, Volume 1(2), pp. 15-26

Chandwani, V., Agrawal, V., Nagar, R., Singh, S., 2015. Modeling Slump of Ready Mix Concrete using Artificial Neural Network. International Journal of Technology, Volume 6(2), pp. 207-216

Colwell, J.E., Batiste, S., Horanyi, M., Robertson, S., Sture, S., 2007. Lunar Surface: Dust Dynamics and Regolith Mechanics. Reviews of Geophysics, Volume 45(2), pp. 1-26

Dholakia, B.H., 2001. Sources of India's Accelerated Growth and the Vision of Indian Economy in 2020. The Indian Economic Journal, Volume 49(4), pp. 27-46

Diaz, A.C., Joy, K.H., Crawford, I.A., Nordheim, T.A., 2015. Constraining the Source Regions of Lunar Meteorites using Orbital Geochemical Data. Meteoritics \& Planetary Science, Volume 50(2), pp. 214-228

Durst, S.M., Sulla, J., Merrell, P.R., 2016. International Lunar Observatory Association: $21^{\text {st }}$ Century Education, Exploration and Enterprise. In: European Lunar Symposium: 94. Amsterdam, May 18-19, 2016

Emery, F.M., Trist, E., 1973. Towards a Social Ecology. Plenum Press, London

Fecht, S., 2016. We Could Be Living on the Moon in 10 Years or Less. Available Online at: https://www.popsci.com/we-could-be-living-on-moon-in-10-years-or-less, Accessed on June 11, 2020

Foing, B., Batenburg, P., Winter, D., Calzada, A., Albalat, A.J., Kleinschneider, A.M., Welch, C., Esser, D., Ivanov, D., Lakk, H., Kapoglou, A., Hazadi, M., Kamps, O., Offringa, M., Pieterse, S., 2016. Highlights From Moon Village Workshops and Studies. In: European Lunar Symposium: 95-96. Amsterdam, May 18-19, 2016

Foing, B., 2017. Lunar Science and Exploration Towards Moon Village. Geophysical Research Abstract, Volume 19

Galileo, G., 1610. Sidereus Nuncius. Venice. English translation by A. Van Helden, 1989. University of Chicago Press, Chicago, IL, USA

Greeley, R., Spudis, P.D., 1981. Volcanism on Mars. Reviews of Geophysics, Volume 19(1), pp. $13-41$

Guarino, B., 2017. Stephen Hawking Calls for a Return to the Moon as Earth's Clock Runs Out. Available Online at: https://www.washingtonpost.com/news/speaking-ofscience/wp/2017/06/21/stephen-hawking-calls-for-a-return-to-the-moon-as- 
earths-clock-runs-out/?noredirect=on\&utm_term=.8ff5ff6c023b, Accessed on June 11, 2020

Hartmann, W.K., 2019. History of the Terminal Cataclysm Paradigm: Epistemology of a Planetary Bombardment That Never (?) Happened. Geosciences, Volume 9(7), p. 1-78

Hiesinger H., Head, J.W., 2006. New Views of Lunar Geoscience: An Introduction and Overview. Reviews in Mineralogy \& Geochemistry, Volume 60, pp. 1-81

Holler, M.W., 2013. Full Report of Mars Generation Survey Results. Available Online at: https://www.exploremars.org/full-report-of-mars-generation-survey-resultsavailable, Accessed on July 32018

Ishimatsu, J., de Weck, O.L., Hoffman, J.A., 2016. Generalized Multicommodity Network Flow Model for the Earth-Moon-Mars-Logistics System. Journal of Spacecraft and Rockets, Volume 53(1)

Juarez, J., 2013. More Than 100,000 Want to Go to Mars and not Return, Project Says. Available Online at: https://edition.cnn.com/2013/08/09/tech/innovation/marsone-applications/index.html, Accessed on June 11, 2020

Kallender, P., 2016. Japan's New Dual-Use Space Policy: The Long Road to the $21^{\text {st }}$ Century. Asie Visions No. 88, Paris, France

Khitab, A., Anwar, W., Mansouri, I., Tariq, M.K., Mehmood, I., 2015. Future of Civil Engineering Materials: A Review from Recent Developments. Reviews on Advanced Material Science, Volume 42(1), pp. 20-27

Lai, M., Gertsch, L., 2013. Excavation of Lunar Regolith with Large Grains by Rippers for Improved Excavation Efficiency. Journal of Aerospace Engineering, Volume 26(1), pp. 97-104

Launius, R.D., 2006. Interpreting the Moon Landings: Project Apollo and the Historians. History and Technology: An International Journal, Volume 22(3), pp. 225-255

Lee, T.S., Ann, K.Y., Chang, B.C., Choi, D., Lee, J., 2014. Solidification of Polymer Concrete using the Artificial Lunar Soil. Earth and Space, pp. 283-290

Lin, T.D., Bhattacharja, S., Powers-Couche, L., Skaar, S.B., Horiguchi, T., Saeki, N., Munaf, D., Peng, Y.N., Casanova, I., 1998. Lunar and Martian Resource Utilization. In: Workshop on Using In Situ Resources for Construction of Planetary Outposts: 12. New Mexico, April 30-May 1, 1998. Lunar and Planetary Institute, USA

Martinez, G.M., Newman, C.N., De Vicente-Retortillo, A., Renno, N.O., Richardson, M.I., Fairen, A.G., Genzer, M., Guzewich, S.D., Haberle, R.M., Harri, A.M., Kemppinen, O., Lemmon, M.T., Smith, M.D., de la Torre-Juarez, M., Vasavada, A.R., 2017. The Modern Near-Surface Martian Climate: A Review of In-situ Meteorological Data from Viking to Curiosity. Space Science Reviews, Volume 212(1-2), pp. 295-338

Matsumoto, S., Yoshida, T., Kanamori, H., Takagi, K., 1998. Construction Engineering Approach for Lunar Base Development. Journal of Aerospace Engineering, Volume 11(4), pp. 129-137

McKay, D.S., Heiken, G., Basu, A., Blanford, G., Simon, S., Reedy, R., Frenc, B.M., Papike, J., 1991. The Lunar Regolith. In: The Lunar Sourcebook, Heiken, G., Vaniman, D.T., French, B.M. (eds.), Cambridge Univ. Press, New York, USA, pp. 285-356

Mendall, W.W., 1998. Role of Lunar Development in Human Exploration of the Solar System. Journal of Aerospace Engineering, Volume 11(4), pp. 106-110

Messina, P., 2016. Moon Village. In: European Lunar Symposium: 1. Amsterdam, May 1819,2016

Metzger, P.T., 2016. Space Development and Space Together: An Historic Opportunity. Space Policy, pp. 1-40 
Mindell, D.A., Uebelhart, S.A., Gerovitch, S., Hoffman, J., Lanford, E., Logsdon, J., MuirHarmony, T., Newman, D., Newsome, S., McGlynn, L., Perry, R., Siddiqi, A., Tomlinson, Z.A., Tylko, J., Weigel, A.L., Young, L.R., 2008. The Future of Human Spaceflight. Available Online at: http://web.mit.edu/mitsps/MITFutureofHumanSpaceFlight.pdf, Accessed on June 11,2020

Nazer, M.Z., 2019. Space-Native Construction Materials for Earth-Independent and Sustainable Infrastructure. Acta Astronautica, Volume 155, pp. 264-273

Niken, C., Tjahjono, E., Supartono, F., 2017. Long-Term Deformation of Beams and Columns of High Performance Concrete. International Journal of Technology, Volume 8(5), pp. 811-819

Phillips, T., 2012. A Hint of Hawaii in the Sands of Mars. Available Online at: https://science.nasa.gov/science-news/science-at-nasa/2012/31oct_hawaii, Accessed on June 11, 2020

Putman, J., 2015. Mars One, the "Third Quarter Effect," and Our Human Journey Into Deep Space. Available Online at: http://www.thespacereview.com/article/2683/1, Accessed on June 11, 2020

Reis, J.M., Ferreira, A.J., 2004. Assessment of Fracture Properties of Epoxy Polymer Concrete Reinforced with Short Carbon and Glass Fibers. Construction and Building Materials, Volume 18(7), pp. 523-528

Sanders, G.B., Larson, W.E., 2011. Integration of In-Situ Resource Utilization into Lunar/Mars Exploration Through Field Analogs. Advances in Space Research, Volume 47(1), pp. 20-29

Sanders, G.B., 2018. Advancing In Situ Resource Utilization Capabilities to Achieve a New Paradigm in Space Exploration. AIAASPACE Forum, pp. 1-8

Trist, E.L., Bamforth, K.W., 1951. Some Social and Psychological Consequences of the Long Wall Method of Coal Getting. Human Relations, Volume 4(1), pp. 3-38

Trist, E. L., Higgin, G. W., Murray, H., Pollock, A. B., 1963. Organizational Choice. Tavistock Publications, London, United Kingdom

Toulmin, P., Baird, A.K., Clark, B.C., Keil, K., Rose, H.J., Christian, R.P., Evans, P.H., Kelliher, W.C., 1977. Geochemical and Mineralogical Interpretation of the Viking Inorganic Chemical Results. Journal of Geophysical Research, Volume 82(28), pp. 4625-4634

Urey, H.C., 1966. The Capture Hypothesis of the Origin of the Moon. The Earth-Moon System, Marsden B.G., Cameron A.G.W. (eds), Springer, Boston, USA

U.S.-Soviet Cooperation in Space, 1985. A Technical Memorandum. U.S. Congress, Office of Technology Assessment, Washington, D.C., USA

van Allen, J.A., 2004. Is Human Spaceflight Now Obsolete? Science. American Association fot the Advencement of Science, Volume 304(5672), pp. 822-824

Wan, L., 2015. Experimental and Computational Analysis of the Behavior of Ultra HighPerformance Concrete, Prestressed Concrete, and Waterless Martian Concrete at Early Age and Beyond. Available Online at: https://www.semanticscholar.org/paper/Experimental-and-Computational-Analysisof-the-of Wan/de1cfee190bcda97165d7665dfc4e35457d960ec\#paper-header,, Accessed on March 30, 2020

Williams, D., Kuipers, A., Mukai, C., Thirsk, R., 2009. Acclimation During Space Flight: Effects on Human Physiology. Canadian Medical Association Journal, Volume 54, pp. 245-256

Yadav, N., Deo, S.V., Ramtekkar, G., 2018. Workable and Robust Concrete using High Volume Construction and Demolition Waste in Sub Tropical Climate. International Journal of Technology, Volume 9(3), pp. 537-548 